\title{
POTENSI Trichoderma viride DALAM MENEKAN SERANGAN Sclerotium rolfsii PADA TANAMAN KEDELAI (Glycine max L.)
}

\author{
Siti Hardianti Wahyuni* \\ Fakultas Pertanian Universitas Graha Nusantara Padang Sidimpuan \\ ${ }^{*}$ Email Korespondensi : sitihardiantiw@yahoo.com
}

\begin{abstract}
Potential of Trichoderma viride to control Sclerotium rolfsii on soybean (Glycine max L.). This research aims to determine the potential of $T$. viride against $S$. rolfsii attack on soybean crop (Glycine max L.). The research was conducted in the field of Faculty of Agriculture, Graha Nusantara University Padangsidimpuan, from May to August 2017. The results showed the highest percentage disease of incidence of $S$. rolfsii at the highest observation of 2, 3, 4 MST (Week After Planting), from W2DO (when planting / 75 gram / polybag) $46.77 \%, 61.35 \%$ and $73.29 \%$. and the lowest was W1D4 (7 days before planting / 300 gram / polybag) $1.8 \%, 2.3 \%$ and $3.41 \%$.
\end{abstract}

Keywords : Potential, Trichoderma viride, Sclerotium rolfsii, Soybean

\section{PENDAHULUAN}

Kebutuhan akan konsumsi kedelai secara nasional meningkat setiap tahunnya, sejalan dengan meningkatnya pertumbuhan penduduk. Konsumsi kedelai pada tahun 2015 mencapai sekitar 2,77 juta ton yang merupakan konsumsi total (rumah tangga dan industri). Diperkirakan pada tahun 2016 kebutuhan akan konsumsi kedelai semakin meningkat sekitar $\pm 2,88$ juta ton. (Direktorat Pangan dan Pertanian 2015).

Salah satu penyebab menurunnya produksi kedelai adalah patogen jamur Sclerotium rolfsii Sacc. S. rolfsii Sacc, merupakan salah satu penyebab penyakit penting pada tanaman kedelai dan jenis kacang-kacangan lainnya di Indonesia (Sastrahidayat et al. 2007). Menurut Muhidin (2004), penyakit rebah semai pada tanaman kedelai diketahui dapat menyebabkan kehilangan hasil sekitar 75$100 \%$. Penyakit rebah semai sering ditemukan serangannya baik di lahan kering, tadah hujan maupun lahan pasang surut dengan intensitas 5-55\% dan tingkat serangan lebih dari 5\% di lapang sudah dapat merugikan secara ekonomi karena tanaman kedelai yang terserang, hasilnya akan rendah dan bahkan sama sekali gagal panen.

Agensia pengendali hayati merupakan salah satu pilihan pengendalian patogen tanaman yang menjanjikan karena murah, mudah didapat, dan aman terhadap lingkungan. Trichoderma sp. merupakan spesies jamur antagonis yang umum dijumpai di dalam tanah, khususnya dalam tanah organik dan sering digunakan di dalam pengendalian hayati, baik terhadap patogen tular-tanah atau rizosfer maupun patogen filosfer. Kisaran inang patogen tanaman yang luas juga menjadi salah satu pertimbangan mengapa jamur ini banyak digunakan (Soesanto 2013). Spesies Trichoderma sp. di samping sebagai organisme pengurai, dapat pula berfungsi sebagai agensia hayati. Trichoderma sp. dalam peranannya sebagai agensia hayati bekerja berdasarkan mekanisme antagonis yang dimilikinya (Wahyuno et al. 2009). Purwantisari (2009), mengatakan bahwa 
Trichoderma sp. merupakan jamur parasit yang dapat menyerang dan mengambil nutrisi dari jamur lain. Kemampuan Trichoderma sp. yaitu mampu memarasit jamur patogen tanaman dan bersifat antagonis, karena memiliki kemampuan untuk mematikan atau menghambat pertumbuhan jamur lain.

$T$. viride mengeluarkan antibiotik dari senyawa viridiol phytotoxin yang dapat menghambat perkembangan patogen, memarasit patogen dengan penetrasi langsung dan juga lebih cepat dalam memper-gunakan $\mathrm{O} 2$, air dan nutrisi sehingga mampu bersaing dengan patogen (Kinerley dan Mukherjee 2010).

Berdasarkan uraian di atas, maka perlu dilakukan penelitian untuk mengenai Potensi Trichoderma viride dalam menekan serangan Sclerotium rolfsii pada tanaman kedelai (Glycine max L.).

\section{BAHAN DAN METODE PENELITIAN}

\section{Waktu dan Tempat}

Penelitian ini dilaksanakan di Lahan Fakultas Pertanian Universitas Graha Nusantara Padangsidimpuan,dengan ketinggian $\pm 480 \mathrm{~m}$ dpl. Penelitian ini mulai dari bulan Mei sampai bulan Agustus 2017.

\section{Pelaksanaan Penelitian}

\section{Isolasi Trichoderma viride}

T. viride diisolasi dari rizosfer tanaman kedelai. Sampel dibuat serial dilusi hingga 10-6. Suspensi diambil 0,1 ml diinokulasikan pada media Potato Dextrose Agar (PDA) yang mengandung Streptomycin $50 \mathrm{mg} / \mathrm{l}$ dan ditumbuhkan pada suhu $27{ }^{\circ} \mathrm{C}$ selama 48 jam. Biakan dimurnikan dengan metode monospora modifikasi dari metode Yuliarni et al. (2010). Konidia jamur disuspensikan dengan akuades pada object glass dengan cara distreak. Biakan ditumbuhkan di media PDA pada suhu $27^{\circ} \mathrm{C}$ selama 10-18 jam. Konidia yang berkecambah dipindah pada media PDA baru. Identifikasi jamur murni dalam media, menggunakan pencirian karakter morfologi $T$. viride dengan kunci identifikasi Barnett dan Hunter (1998) dan dibandingkan dengan karakter isolat $T$. viride koleksi laboratorium yang sudah diidentifikasi sebelumnya sebagai acuan (referensi). Semua isolat yang diidentifikasi dan isolat acuan, diisolasi pada waktu yang sama.

\section{Isolasi S. rolfsii Sacc.}

Jamur $S$. rolfsii Sacc diambil dari koleksi Laboratorium Fakultas Pertanian UGNP. Akar dan batang tanaman bergejala dipotong $(1 \mathrm{~cm} \times 1 \mathrm{~cm} \times 1 \mathrm{~cm})$, meliputi $50 \%$ bagian sehat dan $50 \%$ bagian gejala $S$. rolfsii Sacc. Potongan tanaman dimasukkan ke dalam tiga gelas berisi akuades, alkohol 70\%, akuades masingmasing selama 1 menit, kemudian ditumbuhkan pada PDA dengan Streptomycin $50 \mathrm{mg} / \mathrm{l}$, diinkubasi pada suhu $27{ }^{\circ}$ C. S. rolfsii Sacc. dimurnikan dengan metode monospora sama seperti pemurnian isolat Trichoderma spp. Identifikasi isolat murni dalam media, menggunakan pencirian karakter morfologi S. rolfsii Sacc. dengan kunci identifikasi Barnett dan Hunter (1972) dan dibandingkan dengan karakter isolat $S$. rolfsii Sacc. koleksi laboratorium yang sudah diidentifikasi sebelumnya sebagai acuan (referensi). Semua isolat yang diidentifikasi dan isolat acuan, diisolasi pada waktu yang sama.

\section{Persiapan lahan penelitian}

Area penelitian dibersihkan dari rerumputan, Permukaan tanah diratakan serta dibuat parit draenase untuk menghindari terjadinya penggenangan air bila turun hujan.

\section{Persiapan tanah}

Sebelum dimasukkan ke dalam polibag tanah terlebih dahulu dikeringkan selama 5 jam di bawah sinar matahari, dengan tujuan supaya mikroorganisme 
penyebab penyakit dan benih gulma mati. Tanah yang menggumpal dihancurkan.

\section{Pengisian polibag}

Polibag yang digunakan ialah polibag yang beratnya $5 \mathrm{~kg}$. Sebelum di masukkan ke dalam polibag tanah terlebih dahulu di campur dengan kompos dengan dosis 10 ton/ha ( 60 gram/polibag).

\section{Aplikasi Trichoderma viride}

Jamur $T$. viride diperoleh dari laboratorium Fakultas Pertanian Universitas Andalas Sumatera Barat. T. viride diaplikasikan seminggu sebelum tanam dan pada saat tanam menurut perlakuan, dengan cara dibenamkan lalu ditutup dengan tanah. Satu polibag dibiarkan/tanpa diberikan jamur $T$. viride yang digunakan sebagai kontrol.

\section{Aplikasi Sclerotium rolfsii}

Jamur $S$. rolfsii diperoleh dari laboratorium Universitas Sumatera Utara. Aplikasi S.rolfsii dimasukkan pada saat tanam dengan cara membenamkan miselia yang telah tumbuh pada media PDA ke dalam masing-masing polibag. Jumlah inokulum yang diinokulasikan pertanaman sebanyak $1 / 4$ petridish.

\section{Penanaman}

Penanaman dilakukan dengan cara bersamaan pada setiap perlakuan penanama. Benih kedelai ditanam langsung dalam polibag sebanyak 2 benih/ polibag.

\section{Rancangan Penelitian}

Penelitian ini dilaksanakan dengan menggunakan Rancangan Acak kelompok (RAK) faktorial yang terdiri atas 2 faktor.

Faktor I adalah waktu aplikasi $T$. viride $(\mathrm{W})$ yang terdiri atas 2 taraf :

$\mathrm{W} 1=7$ hari sebelum tanam $\mathrm{W} 2$ = saat tanam

Faktor II adalah dosis Trichoderma viride (D) yang terdiri atas 4 taraf :

$\mathrm{D} 1=75 \mathrm{~g} /$ polibag

D2 $=150 \mathrm{~g} /$ polibag
D3 $=225 \mathrm{~g} /$ polibag

D4 $=300 \mathrm{~g} /$ polibag

\section{HASIL DAN PEMBAHASAN}

\section{Tinggi Tanaman}

Berdasarkan hasil analisis sidik ragam dari pengaruh dosis dan waktu aplikasi Trichoderma viride terhadap serangan Sclerotium rolfsii, diperoleh ratarata tinggi tanaman serta interaksinya pada Tabel 1.1. Dari Tabel 1.1 diperoleh ratarata tinggi tanaman $(\mathrm{cm})$ terbanyak pada pengamatan 2, 3, 4 MST (Minggu Setelah Tanam), dari perlakuan dosis pupuk kompos terdapat pada perlakuan D4 (300 g/polibag) $29.40 \mathrm{~cm}, 32.42 \mathrm{~cm}$ dan 52.92 $\mathrm{cm}$, sementara yang paling rendah adalah terdapat pada perlakuan D1 (75 g/polibag) $26.00 \mathrm{~cm}, 29.70 \mathrm{~cm}$ dan $43.62 \mathrm{~cm}$.

Rata-rata tinggi tanaman pada waktu pemberian pupuk terendah terdapat pada perlakuan W1 (7 hari sebelum tanam) $24.21 \mathrm{~cm}, 30.13 \mathrm{~cm}$ dan $42.19 \mathrm{~cm}$ dan yang paling tinggi W2 (saat tanam) 24.39 $\mathrm{cm}, 30,83 \mathrm{~cm}$ dan $42,78 \mathrm{~cm}$..

Pada perlakuan interaksi antara perlakuan dosis dan waktu pemberian T.viride dapat dilihat rata-rata terbanyak yaitu W1D4 (7 hari sebelum tanam/300 gram/polibag) $34.63 \mathrm{~cm}, 58.73 \mathrm{~cm}$ dan $59.37 \mathrm{~cm}$ dan yang paling rendah W2D1 (saat tanam $/ 75$ gram/polibag) $24.17 \mathrm{~cm}$, $26.10 \mathrm{~cm}$ dan $23.87 \mathrm{~cm}$.

Berdasarkan hasil analisa sidik ragam pengamatan tinggi tanaman menunjukkan bahwa pemberian $T$. viride merupakan faktor yang penting. Hal ini karena $T$. viride merupakan mikrobia tanah yang mempunyai peranan kunci dalam kesuburan tanah. T. viride berperan sebagai mesin yang mengatur daur hara secara simultan sehingga membuat hara tersedia bagi tanaman dan menyimpan hara yang belum dimanfaatkan tanaman. Selain itu, $T$. viride juga melaksanakan sintesis terhadap sebagian besar bahan organik yang bersifat stabil (Sutanto 2002). T. viride juga 
memproduksi zat pengatur tumbuh (ZPT) berupa IAA (Indole Asetic Acid) yaitu salah satu jenis hormon yang dapat memacu pertumbuhan tanaman dengan meningkatkan laju pertumbuhan akar, seperti perpanjangan akar primer serta perbanyakan akar lateral dan akar adventif, yang merupakan suatu keuntungan bagi kecambah dalam meningkatkan kemampuannya untuk lebih merekatkan diri ke tanah, menyerap air, serta nutrisi dari lingkungan sehingga tanaman tersebut dapat bertahan. (Wanjiru 2009; Tarabily et al. 2003). Agustina et al. (2013) mengatakan bahwa Trichoderma spp. tidak hanya melibatkan serangan terhadap patogen pengganggu, tetapi juga melibatkan produksi beberapa metabolit sekunder yang berfungsi meningkatkan pertumbuhan tanaman dan akar, dan memacu mekanisme pertahanan tanaman itu sendiri.

Tabel 1. Tinggi tanaman kedelai

\begin{tabular}{crcc}
\hline Perlakuan & 2MST & 3MST & 4MST \\
\hline W1 & 24.21 & 30.13 & 42.19 \\
W2 & 24.39 & 30.83 & 42.78 \\
\hline D0 & 17.30 & 23.75 & 27.80 \\
D1 & 26.00 & 29.70 & 43.62 \\
D2 & 24.32 & 34.82 & 43.72 \\
D3 & 24.48 & 31.70 & 44.38 \\
D4 & 29.40 & 32.42 & 52.92 \\
\hline W1D0 & 20.60 & 28.80 & 22.40 \\
W1D1 & 28.00 & 30.53 & 46.40 \\
W1D2 & 23.40 & 34.13 & 49.63 \\
W1D3 & 24.43 & 34.43 & 50.17 \\
W1D4 & 34.63 & 58.73 & 59.37 \\
W2D0 & 20.00 & 22.70 & 21.20 \\
W2D1 & 22.00 & 24.87 & 20.83 \\
W2D2 & 23.23 & 25.50 & 22.80 \\
W2D3 & 23.53 & 27.07 & 23.60 \\
W2D4 & 24.17 & 26.10 & 23.87 \\
\hline
\end{tabular}

Keterangan: Angka yang diikuti dengan notasi huruf yang berbeda pada kolom yang sama berbeda nyata pada taraf 5\% Uji Jarak Duncan.

\section{Kejadian Penyakit}

Berdasarkan hasil analisis sidik ragam dari Trichoderma viride dalam menekan serangan Sclerotium rolfsii, diperoleh ratarata kejadian penyakit serta interaksinya pada higstogram. Dari histogram diperoleh rata-rata kejadian penyakit (\%) tertinggi pada pengamatan 2, 3, 4 MST (Minggu Setelah Tanam), dari yaitu W2D0 (saat tanam/75 gram/polibag) $46.77 \%, 61.35 \%$ dan $73.29 \%$ dan yang paling rendah W1D4 (7 hari sebelum tanam/300 gram/polibag) $1.8 \%, 2.3 \%$ dan $3.41 \%$. 


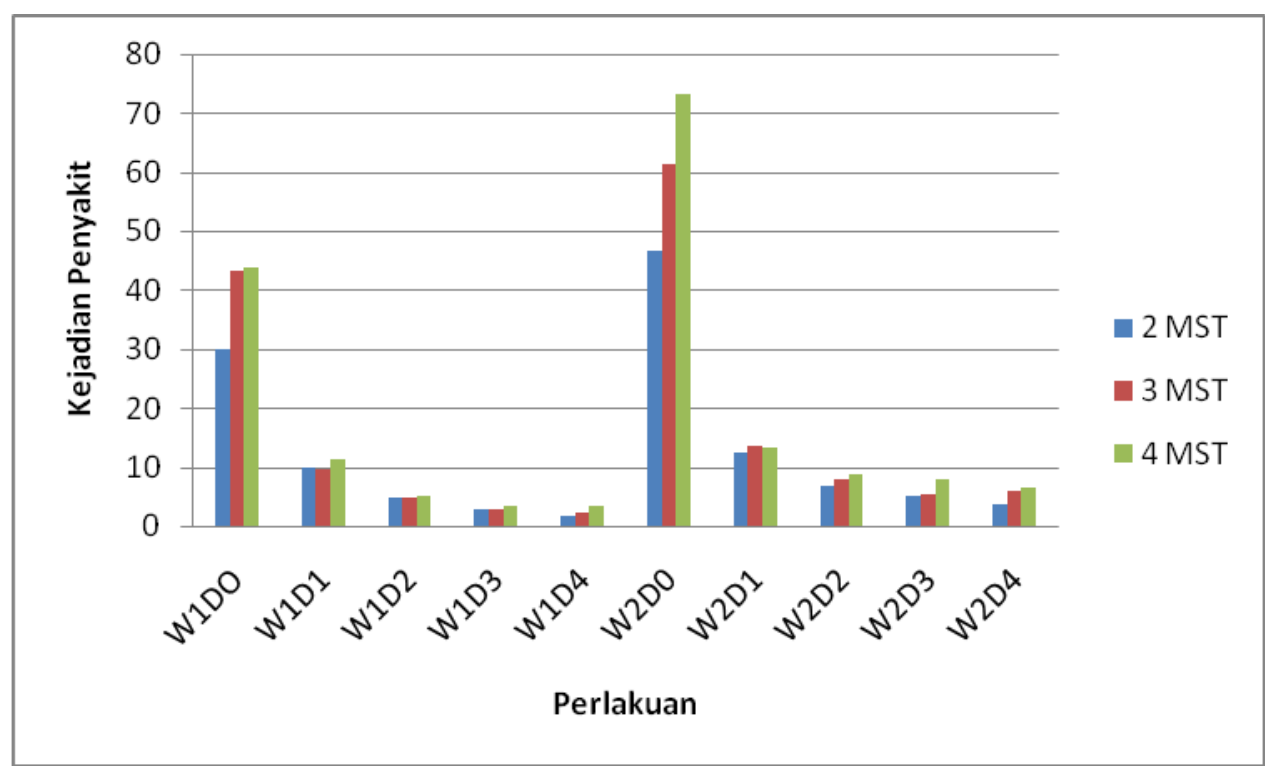

Gambar 1. Histogram kejadian penyakit

Pada pengamatan 4 MST persentase kejadian penyakit pada perlakuan W1D0, W2D0 (kontrol) berbeda nyata dengan perlakuan W1D1. Hal ini dikarenakan pada perlakuan kontrol tidak diaplikasikan $T$. viride yang menyebabkan persentase kejadian penyakit tinggi dibandingkan dengan perlakuan menggunakan jamur antagonis $T$. viride. Sementara dengan diaplikasikannya $T$. viride. menyebabkan terhambatnya pertumbuhan patogen untuk menginfeksi tanaman dikarenakan Trichoderma spp. mempunyai kemampuan kompetisi dengan jamur patogen. T. viride menghasilkan antibiotik berupa gliotoksin, gliovirin dan viridiol yang bersifat fungistatik, gliotoksin dapat menghambat pertumbuhan cendawan dan bakteri, sedangkan viridiol merupakan senyawa yang dapat menghambat cendawan (Hanson dan Howell 2004).

Hasil penelitian menunjukkan bahwa cara pengaplikasian Trichoderma spp. terhadap kejadian penyakit $A$. rolfsii diperoleh persentase terendah dengan aplikasi secara perendaman benih (seed treatment), cara ini merupakan salah satu teknik dalam meningkatkan resistensi benih sehingga dapat menghambat terjadinya pertumbuhan patogen. Jegathambigai et al. (2009) menyatakan bahwa perlakuan benih dengan suspensi
Trichoderma spp. dapat menghilangkan penyakit sementara penggunaan Trichoderma spp. dan Pseudomonas sp. dapat mengurangi kejadian penyakit.

Aslamiyah (2003) menyatakan kompetisi antara dua atau lebih mikroorganisme dapat terjadi jika menggunakan media yang sama dan membutuhkan lingkungan yang sama. Ferreira dan Boley (2006) menyatakan bahwa $S$. rolfsii mampu menginfeksi tanaman jika jumlah miselia yang tumbuh cukup banyak. Untuk mendukung pertumbuhan miselia secara optimal diperlukan nutrisi yang berasal dari bahan organik. Trichoderma spp. mempunyai peluang tinggi untuk berkompetisi merebut tempat hidup dan sumber makanan lebih dulu, lebih cepat menembus dinding sel dan masuk ke dalam sel untuk mengambil zat makanan, serta menghasilkan antibiotik yang dapat membunuh sel cendawan patogen (Gultom 2008).

\section{KESIMPULAN}

1. Persentase kejadian penyakit $S$. rolfsii tertinggi pada yaitu tertinggi pada pengamatan 2, 3, 4 MST (Minggu Setelah Tanam), dari yaitu W2D0 (saat tanam/75 gram/polibag) $46.77 \%, 61.35$ 
2. $\%$ dan $73.29 \%$ dan yang paling rendah W1D4 (7 hari sebelum tanam/300 gram/polibag) $1.8 \%, 2.3 \%$ dan $3.41 \%$.

3. Rata-rata tinggi tanaman tertinggi yaitu W1D4 (7 hari sebelum tanam/300 gram/polibag) $34.63 \mathrm{~cm}, 58.73 \mathrm{~cm}$ dan $59.37 \mathrm{~cm}$ dan yang paling rendah W2D1 (saat tanam $/ 75$ gram/polibag) $24.17 \mathrm{~cm}$, $26.10 \mathrm{~cm}$ dan $23.87 \mathrm{~cm}$.

\section{DAFTAR PUSTAKA}

Agustina I, MI Pinem, F Zahara. 2013. Uji efektivitas jamur antagonis Trichoderma sp. dan Gliocladium sp. untuk mengendalikan penyakit lanas (Phytophthora nicotianae) pada tanaman tembakau deli (Nicotiana Tabaccum L.). Jurnal Online Agroekoteknologi. (1) 4 : 1140-1141

Aslamiyah S. 2003. Optimalisasi dan keefektifan agen biokontrol Trichoderma harzianum dalam mengendalikan penyakit busuk pangkal batang kelapa sawit secara in-vitro [skripsi]. Banda Aceh(ID): Universitas Syiah Kuala. Darussalam

Barnett HL, Hunter BB. 1972, Illustrated genera of imperfect fungi. London(UK): Burgess Publishing Co. 3rd edition. $273 \mathrm{pp}$

Direktorat Pangan dan Pertanian. 2015. Rencana Pembangunan Jangka Menengah Nasional (Rpjmn) Bidang Pangan dan Pertanian 20152019 [internet]. [diunduh pada 2018 Maret 4]. Tersedia pada: http://www.bappenas.go.id/files/37 13/9346/9271/RPJMN_Bidang_Pan gan_dan_Pertanian_2015-2019.pdf.

Ferreira SA, RA Boley. 2006. Sclerotium rolfsii [internet]. [diunduh pada 2015 September 10]. Tersedia pada: http:/www.extento.edu

Gultom JM. 2008. Pengaruh pemberian beberapa jamur antagonis dengan berbagai tingkat konsentrasi untuk menekan perkembangan jamur Phytium sp. penyebab rebah kecambah pada tanaman tembakau (Nicotiana tabaccum L.) [internet]. [diunduh pada 2018 April 15]. Tersedia pada: http://repository.usu.ac.id.pdf

Jegathambigai V, RSW Wijaratnam, RLC Wijesundera. 2009. Trichoderma as a seed treatment to control Helminthosporium leaf spot disease of Chrysalidocarpus lutescens. Int. J. Agric. Scie. 5(6): 720-728

Kinerley CM, P Mukherjee. 2010. Trichoderma virens. [internet]. [diunduh pada 2010 Mei 19]. Tersedia pada: http://genome.jgi.pdf.org/Trivel 1/. Home.html

Purwantisari S, Hastuti BR. 2009. Isolasi dan identifikasi jamur indigenous rhizosfer tanaman kentang dari lahan pertanian kentang organik di Desa Pakis [skripsi]. Magelang(ID): Jurusan Biologi FMIPA UNDIP

Sutanto R. 2002. Penerapan Pertanian Organik, Pemasyarakatan dan Pengembangannya.Yogyakarta(ID) : Kanisius

Tarabily KAH. 2003. Isolasi dan seleksi mikroba diazotrof endofitik dan penghasil zat pemacu tumbuh pada tanaman padi dan jagung. Balai Penelitian Bioteknologi dan Sumberdaya Genetik Pertanian. $128-143$

Wanjiru MM. 2009. Effect of Trichoderma harzianum and arbuscular mycorrhizal fungi on growth of tea cuttings, napier grass and disease management in tomato seedlings. Plant and Microbial Sciences. 13: $305-312$

Yuliarni FF, Suharjono, Bagyo Y, Otto E 2010. Patogenisitas kapang entomopatogen isolat Kalimantan Barat terhadap Lepidoshapes beckii 
Newman hama tanaman jeruk [skripsi]. Malang(ID): Universitas

Brawijaya 